\title{
A ASSISTÊNCIA DE ENFERMAGEM AOS PORTADORES DE HIV/Aids NO VISLUMBRAR DA SUA EPIDEMIA EM RIBEIRÃO PRETO. RELATO DE EXPERIÊNCIA DE UMA EQUIPE DE ENFERMAGEM.
}

\section{THE NURSING ASSISTANCE OF HIV/AIDS MESSENGER IN THE GLIMPSE OF THE EPIDEMIC IN RIBEIRÃO PRETO CITY. EXPERIENCE REPORT OF A NURSING TEAM.}

\author{
Therezinha J.O. Resuto* \\ Sandra Nara Mendes* \\ Marcos Tabary de Oliveira** \\ Edson Luiz Lourenço***
}

RESUTO, T. J. O. et al. A assistência de enfermagem aos portadores de HIV/Aids no vislumbrar da sua epidemia em Ribeirão Preto. Relato de experiência de uma equipe de enfermagem. Rev.Esc.Enf.USP, v.34, n.3, p. 240-3, set. 2000.

\section{RESUMO}

Trata-se de um relato de experiência vivenciada por uma equipe de enfermagem de uma Unidade de Internação, de um hospital geral do interior paulista, ao planejar e prestar assistência de enfermagem ao portador do HIV/Aids, no inicio da epidemia, em 1985.

PALAVRAS-CHAVE: Doenças transmissiveis. Aids. Enfermagem.

\section{ABSTRACT}

This is a report about the experience faced by a nursing team from public hospital in São Paulo city, that took care of HIV/Aids patients in the beginning of the epidemic in 1985.

KEYWORDS: Communicable diseases. Aids. Nursing.

\section{INTRODUÇÃO}

A Unidade de internação de Moléstias InfectoContagiosas da Unidade de Emergência, de um hospital de ensino público e geral do interior paulista, foi criada em 1985, com capacidade para 09 leitos, sendo 03 para pacientes infantis e 06 para adultos.

Até meados do mês de novembro, eram internados pacientes portadores de patologias infecto-contagiosas em geral. A partir do mês de dezembro de 1985, os funcionários foram surpreendidos com a inusitada internação de pacientes portadores do HIV/Aids, ocupando os seis leitos destinados para os adultos. Isto fez com que a unidade assumisse características predominantemente dirigidas a tal patologia que era tão pouco conhecida, causando perplexidade e entravamento à dinâmica funcional.

Em decorrência desta brusca mudança, a equipe de enfermagem, na época composta por 05 enfermeiras, 11 auxiliares e 08 atendentes de enfermagem, passou a desenvolver um trabalho com o objetivo de planejar assistência de enfermagem específica ao paciente portador do HIV/Aids, salientando a importância de se buscar diretrizes para planejar o atendimento aos pacientes, e estimular a participação da equipe neste trabalho.

\footnotetext{
* Enfermeira do Hospital das Clínicas da Faculdade de Medicina de Ribeirão Preto-USP

** Auxiliar de Enfermagem do Hospital das Clínicas da Faculdade de Medicina de Ribeirão Preto-USP

*** Atendente de Enfermagem do Hospital das Clínicas da Faculdade de Medicina de Ribeirão Preto-USP
} 
A admissão do portador do HIV/Aids, acarretou perturbações na rotina normal da unidade assim como, gerou dificuldades significativas em sua capacidade de funcionar, eficientemente.

Sabemos que não é fácil relacionar-se com o paciente em unidade de isolamento, especialmente nas situações mais complexas, como por exemplo trabalhar com eles em situações de rebeldia e agressividade.

A própria condição de isolamento, por si, já apresenta elementos que constituem barreiras à comunicação, à proximidade do paciente envolvendo tanto aspectos fisicos como emocionais (KAMIYAMA, 1979).

Ao iniciarmos nosso trabalho com o paciente portador do HIV/Aids, a equipe enfrentou o medo e o pânico, pois além de transmissivel, sabiamos que era uma doença fatal; além do que tínhamos pouco conhecimento sobre a doença e ignorávamos as características de personalidade dos pacientes.

Hoje, após dezoito anos do aparecimento do HIV, tem-se um quadro claro sobre os danos e conseqüências ocasionados em seus contaminados, pois transcendem o biológico e provocam danos sociais e psicológicos, repercutindo também nas famílias e comunidades.

\section{OBJETIVO}

O objetivo deste trabalho é apresentar a mudança de comportamento, de uma equipe de enfermagem, ao enfrentar e vencer os conflitos dos seus sentimentos iniciais ao procurar estabelecer, com o paciente portador de HIV/Aids, uma relação terapêutica.

\section{METODOLOGIA}

Este trabalho foi desenvolvido durante cinco anos, nos quais a equipe de enfermagem, através de estratégicas reuniões semanais, previamente agendadas, participava de discussões centralizadas nas problematizações das situações profissionais vivenciadas em cada semana.

Discutiam-se os problemas enfrentados pela equipe, os quais eram listados, refletidos e as decisões tomadas eram incorporadas nas rotinas de trabalho e registradas em ata.

As dúvidas, técnico-científicas, eram solucionadas através da busca de literatura, embora na época sua escassez fosse expressiva e, também, através da colaboração de dois médicos: um infectologista e um psiquiatra.
O grupo reuniu-se, semanalmente, durante os cinco primeiros meses. As reuniões passaram a ser mensais, somente depois que a equipe de enfermagem percebeu, que as ansiedades estavam sendo diminuídas. A equipe estava mais preparada para prestar o atendimento ao portador do HIV/ Aids.

Verificamos que houve mudança de comportamento, por parte da equipe de enfermagem, ao vencerem os conflitos dos sentimentos vivenciados no início das internações.

As mudanças ocorreram graças a integração de esforços de toda equipe médica e de enfermagem. Estas mudanças foram agrupadas em quatro fases, que vão desde as dificuldades encontradas no cuidado diário até o medo de se contrair a doença. Salientamos que este agrupamento foi feito pela equipe de trabalho, e as denominações emergiram a partir de consenso estabelecido acerca do conteúdo registrado e discutido nas reuniões.

\section{RESULTADOS E DISCUSSÃO}

A primeira fase, identificada como a Dos Conflitos, iniciou-se com a internação dos pacientes portadores do HIV/Aids, em 1985. Neste período, a equipe de enfermagem vivenciou o medo, o preconceito, a discriminação e a ansiedade frente ao cuidado diário.

Segundo LACAZ (1985), a Aids trouxe a tona, o medo e o pânico, levando as interações interpessoais a alterações significativas, no contexto social em que o indivíduo está inserido. Vem, sobretudo, modificando comportamentos, suscitando ódios, despertando preconceitos e até mesmo lendas.

No âmbito hospitalar, este fato não é divergente, pois aliado ao preconceito surgiu $\mathrm{o}$ medo de assistir estes pacientes.

Toda esta insegurança, acarretou em um número maior de acidentes de trabalho, como por exemplo, os ocasionados por agulhas contaminadas, comadres com excretas caindo ao chão, além de enfrentar a agressividade fisica e moral que os servidores recebiam pôr parte dos pacientes.

Nesta fase, a insegurança da equipe de enfermagem era muito expressiva. Os procedimentos não eram padronizados e pouco se conhecia sobre a doença. Este acontecimento, veio desestruturar toda uma equipe que até então, trabalhava de forma coesa.

Em busca de alternativas, foram realizadas várias reuniões semanais, com a equipe médica e de enfermagem, com o intuito de direcionar 
procedimentos e condutas, mediante as reações de agressividade que eram características do comportamento desses pacientes.

Nesta época, iniciaram os pedidos de demissões e transferências, dos servidores, para outros setores do hospital visto que estes funcionários não se adaptaram à convivência com estes pacientes, tendo inclusive repercussão familiar, como por exemplo, conviver com o preconceito e criticas dos parentes e amigos.

A equipe de enfermagem estava também "doente", por não conseguir administrar sua insegurança e ansiedade: a equipe não tinha domínio sobre o seu medo e preconceito.

$\mathrm{Na}$ segunda fase, denominada de Dupla Agressividade Enfermagem-Paciente, ainda persistia a insegurança quanto à competência técnico-assistencial, e a equipe de enfermagem não havia se estruturado. As condutas não eram padronizadas. A equipe não sabia dizer não, para o paciente, numa atitude de compensá-lo pela rejeição que havia sofrido na primeira fase.

O paciente percebendo esta insegurança, passou a exigir muito de todos os membros da equipe de enfermagem e, com o passar dos tempos, numa atitude de defesa, a equipe começou a agredir os pacientes, com palavras, porque não conseguia racionalizar o seu trabalho.

O cuidado de enfermagem ficou comprometido em favor de solicitações impróprias, feitas pelos pacientes, como por exemplo: solicitavam alimentação fora de horário, consumiam cigarros de forma indiscriminada, pedindo para o servidor comprar mais quando terminava, aumentavam as visitas fora de horário, etc.

Esta atitude de repúdio das pessoas para com o indivíduo e sua doença, estava fundamentada, principalmente, na desinformação.

Na terceira fase, Da Transformação, a equipe de enfermagem passou por duas mutações: uma que foi acidental, ou seja, houve integração de esforços para o desenvolvimento grupal, que cresceu com a troca de experiência, no dia a dia, ocorridas, principalmente, durante as passagens de plantões. Aproveitávamos este momento para a padronização de condutas, que eram seguidas e cobradas por toda equipe de enfermagem.

Outra mutação foi deliberada, ou seja, através de reuniões semanais, onde o grupo contava com a participação de um psiquiatra. Nas reuniões, eram discutidos os problemas enfrentados pela equipe e as atitudes tomadas. Nesta oportunidade, eram ponderados os pontos positivos e negativos, sobre a conduta tomada, avaliada pelo psiquiatra e orientada a melhor maneira de conduzir nosso trabalho diário.
Foram realizadas várias reuniões, visando à atualização de conhecimentos e adaptação de procedimentos técnicos e de rotina, como por exemplo: a descontaminação de materiais, paramentação, atendimento de urgência, horário de visitas, entrada de alimentação e cigarros.

Estas modificações foram necessárias com o objetivo de assistir os pacientes e seus familiares, de forma benéfica, sem prejuízo e desgaste para a equipe de enfermagem.

Quanto ao relacionamento interpessoal enfermagem-paciente, foram adotadas condutas uniformes e atitudes seguras. Dá-se uma relação no âmbito da barganha, através da qual, a equipe de enfermagem procurava negociar com o paciente, o seu cuidado em determinada situação.

A equipe de enfermagem, fez com que o paciente sentisse que a internação era uma necessidade do momento e importante para o seu retorno à sociedade.

Com o conhecimento e as experiências adquiridas, evidenciou-se uma lapidação no nosso trabalho e a equipe de enfermagem aprendeu muito, aproveitando as oportunidades oferecidas pelo próprio paciente e suas relações ao meio e a doença.

A quarta fase, Da Conscientização das Mudanças, foi caracterizada a partir do momento em que passamos a permitir que o paciente expressasse sua raiva ou dor, procurando compreendê-lo e ouvi-lo, sem criticá-lo.

Estas mudanças aconteceram graças a um trabalho onde houve a participação e planejamento de todos os membros da equipe de enfermagem, na execução das atividades diárias.

A equipe de enfermagem conseguiu atingir um nivel de segurança, que não estava apenas nos parâmentos; aprendemos a ter segurança interior, administrando nossos medos e ansiedades e não permitindo mais, que nossos preconceitos interferissem em nossas relações com o paciente.Conseguimos vencer o conflito dos nossos sentimentos iniciais e reasseguramos o valor das técnicas de enfermagem e dos parâmentos de proteção para ter segurança no cuidar.

Salientamos que ainda não conseguimos oferecer aos pacientes portadores do HIV/Aids, uma assistência global, pois a parte psicológica ainda permanecia afetada. Os pacientes necessitavam de acompanhamento psiquiátrico, tanto em situações emergenciais quanto de rotina e, o que há nesse sentido, ainda é insuficiente.

Embora as quatros fases sejam distintas, aconteceram simultaneamente, e o resultado deste processo humanizador, foi o desenvolvimento pleno de todas as potencialidades fisicas, psicológicas, sociais e espirituais da equipe de enfermagem. 
Segundo HEAGARTY(1990), a infecção pelo HIV é mais do que uma intrincada doença infecciosa. A sua característica de fatalidade, de transmissíbilidade e de vínculo a comportamentos tidos como pervertidos, faz com que o portador do HIV, seja discriminado e penalizado. Além disso, esta vivência conflitos emocionais e pessoais de diversas naturezas, como sentimento de culpa, de responsabilidade, enquanto contaminador ou contaminado, medos, perdas e ansiedades múltiplas.

No âmbito hospitalar, o medo e o pânico são atitudes indesejadas e prejudiciais, urgindo-se portanto, a humanização nos hospitais e serviços que prestam atendimento à saúde.

Porém, a humanização do hospital, não se faz sem pessoal suficiente em número e em qualificação. Segundo MEZOMO(1979), humanizar o hospital consiste em recriar laços entre os homens doentes e os homens que se propõem a cuidá-los.

\section{CONSIDERAÇÕES FINAIS}

Destacamos quão imprescindivel é a conscientização e mudança no comportamento, não só da equipe de enfermagem, mas de todas as pessoas envolvidas na área da saúde, que trabalham com o portador de HIV/Aids. Ainda salientamos que aprender a lidar com o sentimento de impotência, mediante um questionamento constante e, as vezes doloroso, de nossos limites enquanto profissional da saúde, é imperativo.
Os pontos negativos e positivos desta nossa experiência, queremos levar aos profissionais de saúde de modo geral, que estão trabalhando com os pacientes portadores do HIV/Aids, no sentido de terem como subsídio, para o desenvolvimento, na sua prática profissional.

Acreditamos que, através do vínculo que a equipe de enfermagem estabelece com o paciente, lhe é conferido um certo poder e respeito que permite conduzir o paciente ao exercício de sua autonomia.

E hoje? Quanto a enfermagem evoluiu nesta assistência? Persiste a negligência, rejeição, medo ou preconceito?

\section{REFERÊNCIAS BIBLIOGRÁFICAS}

HEAGARTY, M. C. Conseqüências psicológicas e sociais. A saúde do mundo,p 18-19, nov-dez, 1990.

KAMIYAMA,Y. Assistência centrada na identidade social: aspectos psico-socias do cuidado de enfermagem ao paciente de hepatite infecciosa. São Paulo 1979. 191p. Tese (Livre Docência)- Escola de Enfermagem, Universidade de São Paulo.

LACAZ, C.S. AIDS: doutrina, aspectos iatrofilosóficos, infecções oportunistas associadas. São Paulo, Sarvier, 1985.

MEZOMO, J.C. Hospital humanizado. São Paulo, CESC- Centro de Desenvolvimento em Administração de Saúde, 1979. 